\title{
Effectiveness of 2D Induced Polarisation \& Electrical Resistivity Tomography in Mapping Fracture Heterogeneity in Foundation Soils.
}

Okechukwu Donald Nnebedum ( $\square$ okechukwu.nnebedum@unn.edu.ng )

University of Nigeria https://orcid.org/0000-0002-3924-4462

Ogbonnaya Igwe

University of Nigeria

Stanley Ikenna Ifediegwu

University of Nigeria

\section{Research}

Keywords: Electrical Resistivity, Tomography, Induced Polarization, Fracture

Posted Date: July 13th, 2021

DOI: https://doi.org/10.21203/rs.3.rs-681484/v1

License: (c) (i) This work is licensed under a Creative Commons Attribution 4.0 International License.

Read Full License 
11 exceedingly popular in mapping near surface discontinuities that can possibly affect engineering

12 structures. The effectiveness of using Induced Polarisation Tomography (IPT) in mapping

13 subsurface fractures was explored. Using the same field way out for both ERT and IPT,

14 investigations were carried out at a failed structure with foundational inhomogeneity in the Nsukka

15 area, Southeastern Nigeria. Four Electrical Resistivity Tomography (ERT) and four Induced

16 Polarisation Tomography (IPT) were carried out. Electrical Resistivity Tomography for profile

17 line one $\left(\mathrm{ERT}_{1}\right)$ and that of the opposite section, $\mathrm{ERT}_{3}$, revealed a fault trending NNW- SSE. This

18 anomaly was also observed on the Induced Polarization Tomography for profile line one (IPT 1 ) as

19 well as that of profile line three (IPT $)$ at the same offset distances, delineating the same fracture

20 zone. A second fault trending in NE-SW was mapped by the Electrical Resistivity Tomography

21 for profile line two $\left(\mathrm{ERT}_{2}\right)$ and Electrical Resistivity Tomography for profile line four $\left(\mathrm{ERT}_{4}\right)$. The 
22 fault was also visible in the Induced Polarization counterparts, $\mathrm{IPT}_{2}$ and $\mathrm{IPT}_{4}$. Field validation

23 along mapped trends recorded subtle cracks on the foundation along the same trend detected by

24 the IPT as well as the ERT.

25 Keywords: Electrical Resistivity, Tomography, Induced Polarization, Fracture.

\section{$27 \quad 1.0 \quad$ INTRODUCTION}

28 Soil's suitability for engineering purposes depends largely on their ability to remain in place and

29 to support either permanent or transient loads that may be placed on them (Roy and Bhalla, 2017).

30 In other words, the success of any engineering structure directly placed on the earth's surface

31 would depend on the support provided by the foundation materials that bear the load of the

32 structure alongside other factors. (Terzaghi et al., 1996; Osinowo and Falufosi, 2018). Apart from

33 geo-structural factors, other factors that can threaten the stability of engineering structures include

34 poor building design, poor materials, and inexperienced personnel (Adewuyi and Philips, 2018),

35 with a number of such failures recorded (Ayedun et al., 2012; Oyedele and Olorode, 2011; Soupois

36 et al., 2007).A case of a failing foundation of a massive auditorium nearing completion at the

37 University of Nigeria Nsukka is being investigated.Fractures or cavities within the earth materials

38 bearing the structure have been proposed as likely contributors to this failure. The area is underlain

39 by Campano-Maastritchian earth materials belonging to the Anambra basin (Reijers, 1996; Obi

40 and Okogbue, 2004) of which two post Santonian faults trending NW-SE and NE - SW that

41 affected these sediments around Enugu area have been reported (Amogu et. al., 2010). Popular

42 analysis commonly used by engineers in determining ultimate bearing capacity of soils like

43 Prandtl's Analysis and Terzaghi's Analysis runs on the assumption of homogeneous and isotropic

44 soil mass (Sitharam, 2013) and may not always capture the presence of cavity or fault which 
45 constitute inhomogeneity. The use of Electrical Resistivity Tomography is a well-known technique

46 for detecting subsurface inhomogeneity associated with fractures. (Chieh-Hou et al., 2000;

47 Samouelian et al., 2005; Nguyen et al., 2005; Han-lun et al., 2010; Reynolds, 2011; Ugwu and

48 Ezema, 2013; Oyeyemi, 2016; Coker, 2017; Osinowo and Falufosi, 2018).

50 Also, Time domain Induced Polarisation is another technique capable of detecting cavities and

51 fractures, though it is yet to be deployed for this purpose in this region. Vogelsang (1995) described

52 a type of polarization termed boundary-layer polarization, though weaker than metallic

53 polarization, which develops an accumulation of cations at the boundary layer of electrolyte and

54 then spreads over the pore walls of silicate rocks. Telford et al., (1990) also described a membrane

55 or electrolytic polarization where it was noted that the rock structure must be somewhat porous to

56 permit the flow of current when metallic minerals are absent. Faulting can generate this type of

57 polarization, especially when it juxtaposes two different blocks or brings two fluids that are slightly

58 different chemically. Aside from juxtaposition, open fractures create secondary porosity that are

59 usually high conduits for the passage of fluid, which in turns allows for the generation of IP effect

60 upon abrupt switching off-and-on of current supply (Telford et al., 1990). Also, fractures filled

61 with conductive clays also generate a polarization effect when the current is abruptly terminated.

63 Schmutz et al. (2011) has used the Spectral Induced Polarization (SIP), a phase and magnitude

64 dependent Induced Polarisation measured over a range of frequencies, to detect fractures as well

65 as distinguish between the open and clay filled ones. In the time domain Induced Polarisation, the

66 delay in the decay of voltage after current is turned off and then rises to its actual state after it is

67 turned on (overvoltage) is measured as a function of time (Reynolds, 2011). 
69 In this paper, our goal is to show that conventional 2D Time domain Induced Polarization

70 Tomography (hereafter known as IPT) is effective in delineating inhomogeneity or anisotropy

71 within foundation earth material as well as the very well-known 2D Electrical Resistivity

72 Tomography (ERT).

73

2.0 THE GEOLOGY OF THE STUDY AREA

75 The study area (Figure 1) forms a part of the Campano-Maastrichtian Anambra Basin (Reyment 76 1965; Shorts and Stauble, 1967; Obi and Okogbue, 2004; Nwajide, 2013). The geologic formation 77 of the Anambra Basin that underlies the area under study is the Maastrichtian Ajali Formation.

78 The Formation is described as medium to coarse grained sandstones and conglomerates (Nwajide, 79 1990; Obi and Okogbue, 2004). Nwajide (1990) further described the grain size as angular to 80 subangular quartz-arenites. It is whitish in colour when fresh with iron stains and brownish in

81 colour when weathered or exposed to atmospheric conditions. This is an indication of relatively 82 high iron content. The thickness of the Ajali Formation at outcrops ranges from $25 \mathrm{~m}$ to $50 \mathrm{~m}$ (Obi 83 and Okogbue, 2004), with sufficiently thick weathered overburden typically being reddish brown 84 in colour. Syn-depositional structures like trough and planar cross-bedding with mud-draped 85 foresets, over-turned foresets, flaser and herringbone bedding, large mud clast as well as 86 Ophiomorpha trace fossils suggest a tidally influenced fluvial-and fluvial channel environment of 87 deposition (Obi and Okogbue, 2004). Post depositional structures like fractures (joints and faults) 88 have been reported as well. Amogu et al. (2010) mapped two post Santonian faults trending NW89 SE and NE - SW that affected the Campano-Maastrichtian sediments around Enugu area. 
91 Although Sitharam (2013) listed the presumed allowable bearing pressure for cohesionless soils -

92 coarse grained sandstone $(440 \mathrm{kPa})$ and medium grained sandstone $(240 \mathrm{kPa})$ which are

93 favourable, the presence of fractures in foundation soils can cause great harm to engineering

94 structures placed directly on them. (Terzaghi et al., 1996; Osinowo and Falufosi, 2018). Figure 1

95 gives an overview of the geology in the study area.

96

\section{Legend}

- LGA

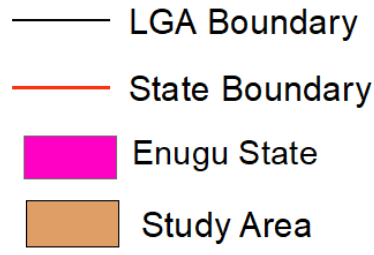

98

99 Figure 1. Location and Geology of the study area

100

101

\subsection{Materials and Method}

102

\subsection{Electrical Resistivity}

103

Rocks conduct electric current in three ways, namely: electrolytic, electronic (ohmic) and

dielectric means (Reynolds, 2011). In most rocks and especially clastic rocks (sedimentary

105 rocks), conduction is carried out by pore fluids acting as electrolytes, where the mineral grains contribute insignificantly to the overall conductivity of the rock. The only condition where mineral grains will contribute sufficiently to overall rock conductivity is when the grains themselves are good electronic conductors (Reynolds, 2011). Based on the foregoing, it is 
110 resistivity model and provides geological meaning to modeled resistivity.

$$
\rho=a \boldsymbol{\phi}^{-m} \boldsymbol{S}^{-n} \rho_{w}
$$

$$
\rho / \rho_{w}=a \phi^{-m}
$$

113 where

$114 \rho$ and $\rho w$ are the effective rock resistivity, and the resistivity of the porewater, respectively.

$115 \phi$ is the porosity; $S$ is the volume fraction of pores with water.

$116 a, m$ and $n$ are constants where $0.5 \leq a \leq 2.5,1.3 \leq m \leq 2.5$, and $n \approx 2$.

$117 \quad F$ is the Formation Resistivity Factor

119 Equation (1) shows that with increase in porosity, a reduction in the bulk or effective resistivity

120 is expected. As porewater saturation increases, effective resistivity reduces. For resistivity of 121 porewater, it will increase with increasing bulk resistivity.

122 Porosity is a major influencer of effective resistivity especially when the resistivity of 123 porewater is tending towards unity as can be deduced from Equation (2) (Archie, 1942;

$124 \quad J a c k s o n$ et al., 1978; Ioannidis et al., 1997; Keary et. al, 2002; Chen et al., 2008; Reynolds, 

square of porosity as shown in equation 3 below.

$$
\rho \approx 1 / \phi^{2}
$$

128 Fractures enhance secondary porosity of rocks. As a result, they are expected to display lower 129 effective resistivity than the unfractured blocks in a 2D resistivity section.

130 However, Apparent resistivity, $\rho_{a}$, is directly measured during field and it is derived by the 131 product of measured resistance $(\mathrm{R})$ and a geometric factor $(\mathrm{K})$ as shown in equation 4 (Reynolds, 132 2011). The geometric factor is dependent on the electrode configuration used in data collection 133 which is governed by ohmic law. Geometric factor for Werner array is given in equation 5. True 134 resistivity is derived by the inversion of the apparent resistivity.

$$
\rho_{a}=R * k
$$

$$
K=2 \pi a
$$

138 Where:

$139 \quad \rho_{a}$ is the apparent resistivity;

$140 \quad R$ is measured resistance

$141 \quad K$ is Geometric Factor;

142 a is electrode spacing; 


\section{$144 \quad 3.2 \quad$ Time Domain Induced Polarisation}

145 Upon applying current to the ground and switching it off after a moment, an overvoltage builds up 146 which decays (Reynolds, 2011; Telford et al., 1990) as shown in Figure 2. The magnitude of the

147 observed voltage (Vo) is equal to the actual voltage (V) as a result of the passage of current and in 148 addition, a polarization voltage $(\mathrm{Vp})$ is caused by either grain, electrolytic, macroscopic, or ionic 149 processes. These processes are well documented (Reynolds, 2011; Vogelsang, 1995; Telford et al., 150 1990). Switching off the applied current, the voltage drops within an imperceptibly brief period of 151 time by an amount $\mathrm{V}$, leaving a residual voltage called overvoltage $(\mathrm{Vp})$ that decays with time. A 152 measure of the generated induced polarization (IP) effect is the ratio $\mathrm{Vp} / \mathrm{Vo}$, which is known as 153 Chargeability which is normally expressed in terms of millivolts per volt or percent. Measurement 154 of overvoltage ( $\mathrm{Vp}$ ) via instrument is usually done at a fixed time, typically $0.5 \mathrm{~s}$ when current 155 cutoff and decay would be noted at discrete intervals of about 0.1s (Reynolds, 2011). Integral of 156 the values with respect to time gives the area under the curve (Figure 2a). Mathematically, it is 157 expressed as shown in equation 4.

158 Figure 2. Two forms of measurement of overvoltage $\left(V_{p}\right)$ at (a) discrete time interval and (b) 159 by the area below the overvoltage curve, $\mathbf{A}$.

160

$$
\mathrm{M}=\frac{1}{v_{0}} \int_{t_{1}}^{t_{2}} v(t) \mathrm{d} t
$$

162 Where:

$163 \mathrm{M}$ is Chargeability 
164 Vo is observed voltage

$165 \mathrm{Vp}$ is the polarization voltage or overvoltage; $\mathrm{t}$ is time

166 Field measurement of true chargeability described by equation 4 is usually not very practical

167 (Reynolds, 2011) however, a ratio of the integral with Vo gives the apparent chargeability (Ma)

168 which is measurable and has its units in time (milliseconds). The expression is given in equation

1695.

170

171

$$
\mathrm{Ma}=\frac{1}{v_{0}} \int_{t_{1}}^{t_{2}} v_{p}(t) \mathrm{d} t=\frac{A}{v_{0}}
$$

172

173 Where:

174 Ma is Apparent Chargeability

175 Vo is observed voltage; $\mathrm{Vp}$ is the polarization voltage or overvoltage.

$176 \mathrm{t}$ is time; $\mathrm{A}$ is area beneath the decay curve.

177 One main advantage of recording $\mathrm{Ma}$ is that it reduces noise from cross-coupling cables alongside

178 those from background potentials (Reynolds, 2011). Field data used for the modeling IP

179 tomographic sections in the study utilized the Ma values recorded with ABEM SAS 1000.

180

\subsection{Data Acquisition and Processing}


182 Reconnaissance studies carried out at the study area aided the design of the survey as shown in

183 Fig. 3. Resistivity and Induced Polarization data were acquired along the designed profile lines 184 using ABEM Terrameter SAS 1000. Each of the profile lines was executed using a Werner (Alpha)

185 Array method (Nguyen et al., 2005) with a minimum electrode spread (a) of 10m and a maximum 186 of $30 \mathrm{~m}$ i.e. $\mathrm{n}=3$. The ratio of the median depth of investigation (Ze) of Werner Alpha to the

187 minimum electrode spread (a) is 0.519 (Loke, 2000). A maximum electrode spread of 30m should 188 give an estimated depth of investigation of about $15 \mathrm{~m}$. This depth of investigation seemed 189 satisfactory for foundation soil investigation since most foundations do not exceed $7 \mathrm{~m}$ depth 190 except for high rising structures.

191 Electrodes were laid at 10m intervals along each profile line and their coordinates were taken with 192 the help of a Global Positioning System (GPS). These coordinates were further plotted in Google 193 Earth application to quality control their spatial positions. With the accurate determination of the 194 electrode positions, observed anomalies on profile sections would easily be tied to the zone of 195 foundation instability.

197 The apparent electrical resistivity and chargeability data collected were arranged to Block Model 198 data format, displayed, and dispiked where necessary using RES2DINV@ software. Block Model 199 format is reported to yield a good result for fault modeling (Genelle et al., 2012). Subsequently, 200 data were inverted employing a least-squares inversion technique (Loke and Barker,1996; Loke, 201 2004; Osinowo and Falufosi, 2018). Half-cell width model refinement (Loke, 2004) was applied 202 due to larger resistivity values observed at the uppermost layer for better inversion results. The 203 process displayed acceptable tomographic sections for both Electrical Resistivity and IP sections. 


\subsection{RESULTS AND DISCUSSION}

208 The result of electrical resistivity for profile line one is given in Figure 4a. Figure 4a (i) is the 209 apparent Electrical Resistivity data displayed in a pseudo-section while Figure 4a (ii) is the

210 theoretically calculated section. Figure 4a (iii) is the inverted section which is the true resistivity

211 image of the subsurface termed ERT1. A good resemblance exists between the apparent and the

212 calculated sections revealing high input data integrity (Loke, 2004). ERT1 shows a vertical

213 anomalous zone of relatively low resistivity $(<600 \Omega \mathrm{m})$ at an offset distance of about $70-90 \mathrm{~m}$.

214 This vertical anomalous zone most likely possesses higher porosity or a very conductive interval,

215 thereby causing a drastic drop in the resistivity (equation 1-3). Based on the geology a probable

216 geologic event that could yield such a phenomenon is a fracture. Fractures increase secondary

217 porosity and as well create conduits for fluid migration. Fluid like groundwater is generally

218 mineralized and can serve as a weak electrolyte which in turn reduces the bulk resistivity of

219 materials. Figure $4 \mathrm{~b}$ is the result of the 2D Induced Polarization survey for profile line one.

220 Figure $4 \mathrm{~b}$ (i) is the pseudo-plot of the apparent chargeability while Figure $4 \mathrm{~b}$ (ii) is the theoretically

221 calculated section. A good match observed in both images shows good data quality which

222 subsequently yields a reliable inversion (Loke, 2004). The inverted section is given in Figure 4b

223 (iii) which is the true chargeability result for the Induced Polarisation survey for profile line one,

224 hereafter referred to as IPT1. Figure 4b (iii) shows anomalously high chargeability at the same

225 spatial position observed in ERT1 (Figure 4a (iii)). The IPT1 anomaly ranges from $7.77 \mathrm{msec}-$

$2268.98 \mathrm{msec}$, as against the background values of $0.5 \mathrm{msec}$ to $3.0 \mathrm{msec}$. IPT1 further supports the

227 presence of fracture in the region of profile one. Conductive interval acts as capacitors that tend to 
228 build up charges which will decay with time after the induced current is turned off. In the case of

229 groundwater filling fracture conduits, the stored electrical charges tend to decay over time after

230 the current is put off, giving rise to higher chargeability within the zone of occurrence.

231

232

233

234

235

236

237

238

239

240

241

242

243

244

245

246

247

248

249

250

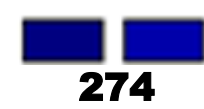

274

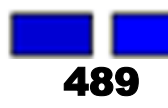

489

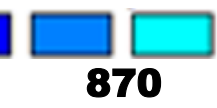

870
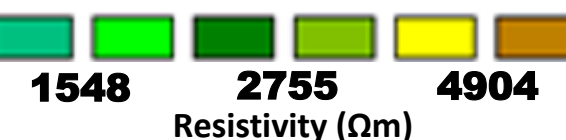

Figure 4 (a) Legend

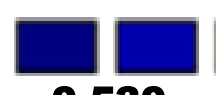

0.530

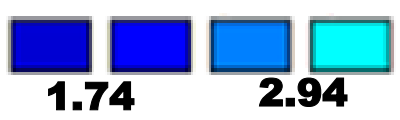

1.74

2.94

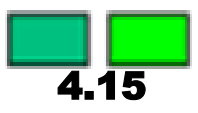

Chargeability (Msec)

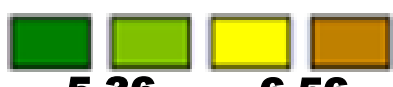

6.56

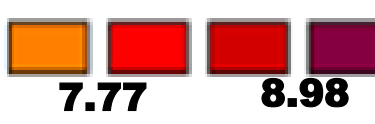

Figure 4 (b) Legend

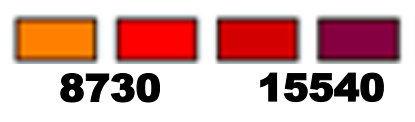

$\mathbf{7 . 7 7}$

$\mathbf{8 . 9 8}$

Figure 4 Tomography Result for Profile line One. (a) Electrical Resistivity Tomography for profile line one (ERT1), (b) Induced Polarization Tomography for profile line one (IPT1)

The result of surveys on profile line two is shown in Figure 5. Figure 5a (i) is the pseudo-plot of the apparent resistivity while 5a (ii) is the theoretical calculation for the same section. Similarities in the patterns displayed by the pseudo and the calculated section justify the inversion result shown in Figure 5a (iii) which is the Electrical Resistivity Tomography for profile line two (ERT2). Two anomalous zones appeared on this section at an offset distance of $65 \mathrm{~m}-75 \mathrm{~m}$ and $90 \mathrm{~m}-105 \mathrm{~m}$ possessing a resistivity value ranging from $107 \Omega \mathrm{m}-695 \Omega \mathrm{m}$, lower than the adjacent resistivity values. The depth of the anomalous zone in the first offset seems to be deeper than $16 \mathrm{~m}$. This vertically inclined anomalous zone at offset distance ranging from $65 \mathrm{~m}-75 \mathrm{~m}$ in ERT2 seems to be mimicking the resistivity behavior typical of a fault zone.

The Induced Polarisation result for profile line two is given in Figure 5b. A pseudo-section of the measured apparent chargeability is displayed in Figure 5b (i) while that of the calculated apparent 
251 chargeability is shown in Figure 5b (i). The inversion result for the measured apparent 252 chargeability for profile line two (IPT2) is given in Figure 5b (iii). At offset distance of $65 \mathrm{~m}-90$

$253 \mathrm{~m}$, higher chargeability values (200 msec $-395 \mathrm{msec})$ exceeding the background lower values are

254 noticed. IPT2 reveals an anomaly on profile line two at offset distance and orientation similar to 255 that of ERT2.
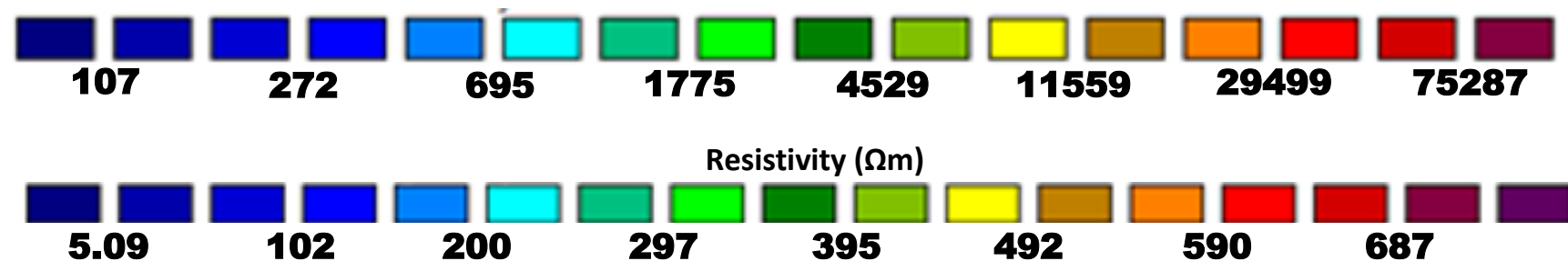

Figure 5 (b) Legend

262

Figure 5. Tomography Result for Profile Line Two. (a) Profile Line Two Electrical Resistivity Tomography (ERT2), (b) Profile line Two Induced Polarization Tomography (IPT2).

267 The result of surveys conducted on profile line three is given in Figure 6. The measured apparent 268 resistivity for profile line 3 is displayed in Figure 6a (i). The theoretically calculated apparent 269 resistivity for the same section is presented in Figure 6a (ii). Good similarity exists in the patterns 270 observed in both Figure 6a (i) and (ii) showing a reliable inversion process whose result is 271 displayed in Figure 6a (iii). At offset distance ranging from about $75 \mathrm{~m}-105 \mathrm{~m}$, an anomalous 272 zone with a resistivity of about $203 \Omega \mathrm{m}$ and less is observed on ERT3 (Figure 6a (iii)). 
273 Figure $6 \mathrm{~b}$ contains the result of the chargeability survey performed on profile line 3 . The measured 274 apparent chargeability is displayed in a pseudo-section given in Figure $6 \mathrm{~b}$ (i). Figure $6 \mathrm{~b}$ (ii) is the 275 calculated apparent chargeability section for the same profile line. The inverted result is presented

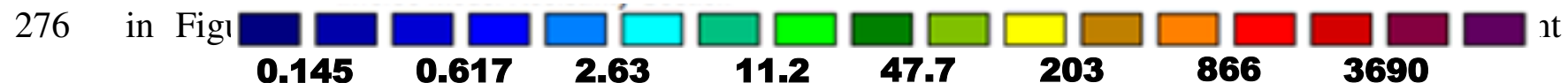

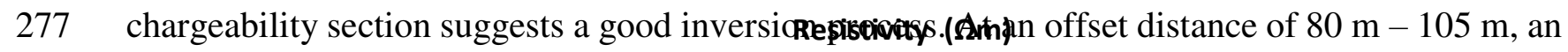

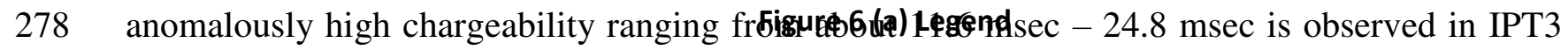
279 (Figure 6b (iii)).

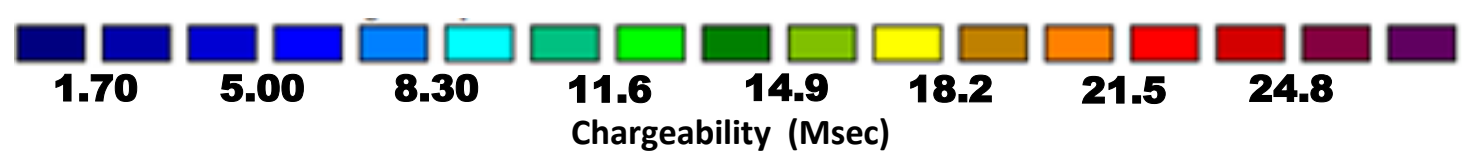

287 Figure 6. Tomography Result for Profile Line Three. (a) Profile Line Three Electrical Resistivity 288 Tomography (ERT3), (b) Profile line Three Induced Polarization Tomography (IPT3)

290 Profile line four results are displayed in Figure 7. The Electrical Resistivity results in Figure 7a 291 while that of Induced Polarization in Figure 7b. Figure 7a (i) is the measured apparent resistivity 292 for the profile line four survey while the calculated apparent resistivity for the same profile line is 293 given in Figure 7a (ii). The inversion of the measured apparent resistivity data yielded a true 294 resistivity section for the profile line, ERT4, presented in Figure 7a (iii). A good resemblance in 295 the pseudo-section of the measured and the calculated apparent resistivity implies a stable 
296 inversion process. At an offset distance of $40 \mathrm{~m}-55 \mathrm{~m}$, an inclined zone of anomalously low

297 resistivity is observed on the ERT4. The resistivity of this zone ranges from $169 \Omega \mathrm{m}-388 \Omega \mathrm{m}$

298 (Figure 7a (iii)).

299 Figure 7b (i) is the measured apparent chargeability pseudo-section for profile line four. The

300 calculated apparent chargeability is given in Figure 7b (ii). The inversion result (IPT4) of the

301 measured apparent chargeability for profile line four is presented in Figure $7 \mathrm{~b}$ (iii). The good

302 similarity between the measured and the calculated apparent chargeability suggests a reliable

303 inversion process. Main Anomalous chargeability was observed at an offset distance of $50 \mathrm{~m}-$

$30465 \mathrm{~m}$ with values ranging from about $195 \mathrm{msec}-296 \mathrm{msec}$. Another anomalous zone of a smaller

305 scale was noticed at $70 \mathrm{~m}-85 \mathrm{~m}$. Although the latter anomalous zone is smaller in terms of size,

306 higher chargeability (over $603 \mathrm{msec}$ ) is recorded at this interval.

307

308

309

310

311

312

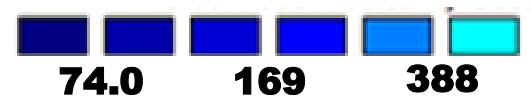

74.0

169

388

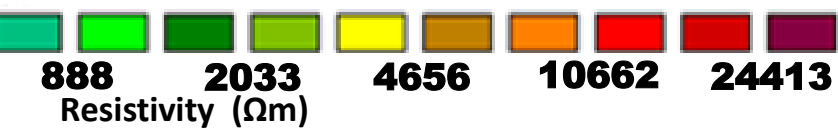

Figure 7 (a) Legend
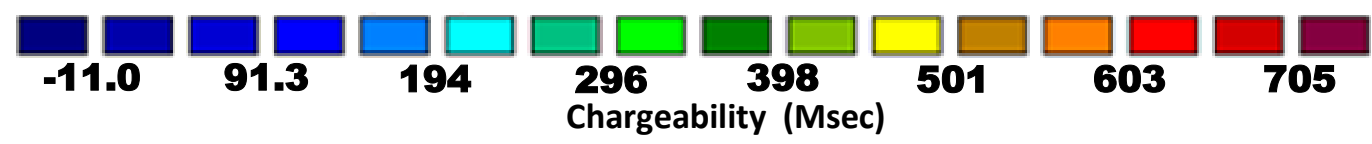

Figure 7 (b) Legend

313 Figure 7. Tomography Result for Profile Line Four. (a) Profile Line Four Electrical Resistivity

314 Tomography (ERT4), (b) Profile line Four Induced Polarization Tomography (IPT4)

316 Inclined anomalous zones of low resistivity observed on the Electrical Resistivity Tomography

317 (ERT) sections suggest that these surveys intercepted fractures within the foundation soils. The 
318 outcome of correlating results of opposite profile lines validates the presence of fractures (Figures

$3198 \& 9)$.

320

321

322 Figure 8 compared the results of profile line one and that of line three (Figure 8d). Figure 8a is a

$3233 \mathrm{D}$ representation of the measured apparent resistivity of profile line three (Figure 8a (i)) and that

324 of profile line one (Figure 8a (ii)). At an offset distance of about $80 \mathrm{~m}$, low measured apparent

325 resistivity ran from profile line one to profile line three. This is represented by a blue-coloured

326 depression in Figure 8a (ii) and Figure 8a (i) respectively. Figure 8b correlates the ERT3 (Figure

$3278 \mathrm{~b}$ (i)) and ERT1 (Figure 8b (ii)). This correlation model the fracture plane indicated by the broken

328 line (Figure $8 \mathrm{~b}$ ). The trend of this fracture is NNW-SSE.

329

330

331

332

333

334

335

336

337

Legends for Figure 8 (b) same as ERT1 (Figure 4 a) and ERT3 (Figure 6a)

Figure 8 (a) Legend

338

339 Figure 8. Fracture Zone 'A' delineation. (a) A 3D plot of measured apparent resistivity for profile

340 line Three and Profile line one revealing fracture zone. (b) 2.5D view of ERT1 - ERT3 revealing 
341 fracture zone (c) 2.5D view of IPT1 - IPT3 revealing fracture zone, (d) Google earth image 342 showing profile lines I and 3.

344 Legends for Figure 9 (a) same as ERT2 (Figure 5a) and ERT4 (Figure 7a)

345 Legends for Figure 9 (b) same as IPT2 (Figure 5b) and IPT4 (Figure 7b)

346 Figure 9. Fracture Zone 'B' delineation. (a) 2.5D view of ERT2 - ERT4 revealing fracture zone 347 (b) $2.5 \mathrm{D}$ view of IPT2 - IPT4 revealing fracture zone.

349 The correlation of the IP results of profile line three and profile line one is presented in Figure 8c.

350 This result clearly shows the strength of Induced Polarization Tomography (IPT) in imaging the 351 same fracture trend identified by the ERT.

352 More so, the correlation of results of profile line two with that of profile line four detected another

353 fracture trending in the NE-SW direction (Figure 9). Figure 9a images the fault from ERT4 (i) and 354 ERT2 (ii). Figure 9b reveals that the same fault can be imaged using Induce Polarization 355 techniques.

356 Field validation (Figure 10) shows visible cracks on the foundation of structures further confirming

357 the presence of fractures in the site area. Although most of the cracks reveal a north-southerly 358 (Figure 10 i-iv, vii) trending fractures, some east - westerly (Figure $10 \mathrm{v}$-vii) are present. Based 359 on the ERT and IPT results, two fracture (fracture zone A and B) trends are delineated as shown

360 in Figure 11. This deduction agrees with Amogu et al. (2010) who mapped two post-Santonian 361 faults trending NW-SE and NE - SW that affected the Campano-Maastrichtian sediments.

362 Figure 10. Field photographs validating the presence of a fracture.

363 Figure 11. Delineated fracture zones on Google Map view. 


\subsection{CONCLUSION}

366 This study demonstrates the suitability of the 2D Induced Polarization technique as well as 2D

367 Electrical Resistivity in mapping inhomogeneity introduced by fractures in foundation soils; both

368 techniques mapped the two major fracture zones (trending in an NNW- SSE direction, as well as

369 NE-SW direction) in the study area.

\section{REFERENCES}

373 Adewuyi IO, Philips FO (2018) Integrated Geophysical and Geotechnical Methods for Pre374 Foundation Investigations. Journal of Geology \& Geophysics 8(1): 1-9.

375 Amogu DK, Ekwe AC, Onuoha KM (2010) Kinematics of faults and joints at Enugu area of the 376 Anambra basin. Journal of Geology and Mining Research 2(5): 101-113.

Archie GE (1942) The electrical resistivity $\log$ as an aid in determining some reservoir 379 characteristics. Trans Am Inst Min Metall Pet Eng. 146(1):54-62.

380 Ayedun C, Olufemi D, Akinjare O (2012) An Empirical Ascertainment of the Causes of Building 381 Failure and Collapse in Nigeria. Mediterranean Journal of Social Sciences 3(1): 313-322.

382 Chen M-AP, Riedel M, Spence GD, Hyndman RD (2008) Data report: a downhole electrical 383 resistivity study of northern Cascadia marine gas hydrate: The Expedition 311 Scientists, 384 Proceedings of Integrated Ocean Drilling Program. Washington DC 311(1): 1-27.

386 Chieh-Hou Y, Ping-HU C, Jin-Jun C (2000) Fault Detection by 2D Resistivity Inversion 387 on a Topographic Area. Terrestrial Atmospheric Oceanic Science 11(4):909-928.

389 Coker OJ, Akinpelu TA, Makinde V, Nasir NA, Bello R (2017) Combined Geophysical and 390 Geotechnical Techniques for Assessment of Foundation Failure: A Case Study Lagos State 391 Polytechnic Ikorodu, Lagos, Nigeria. International Refereed Journal of Engineering and Science 392 6(7):38-44. 
394 Genelle F, Sirieix C, Riss J, Naudet V (2012) Monitoring landfill cover by Electrical

395 Resistivity Tomography on an Experimental Site. Engineering Geology 145-146(1): 18-29.

397 Han-Lun H, Brian J Y, Chien-chih C, Yue-Gau C (2010) Bedrock Detection Using 2D Electrical

398 Resistivity Imaging Along the Peikang River, Central Taiwan. Geomorphology 114(1):406-414.

400 Ioannis FL, Dimitrios R, Ioannis G, Filippos IL (2002) Geophysical Imaging of Faults and Fault 401 Zones in the Urban Complex of Ano Liosia Neogene Basin, Greece: Synthetic Simulation 402 Approach and Field Investigations. Journal of Electrical \& Electronics Engineering Special Issue: $403 \quad 269-285$.

Ioannidis MA, Kwiecien MJ, Chatzis I (1997) Electrical Conductivity and Percolation Aspects of 406 Statistically Homogeneous Porous Media. Transport in Porous Media 29(1):61-83.

Jackson PD, Smith DT, Stanford PN (1978) Resistivity-Porosity - particle shape relationship for 409 marine sands. Geophysics 43(6): 1250-1268.

411 Keary P, Brooks M, Ian H (2002) An Introduction to Geophysical Exploration. Blackwell 412 Science, Oxford UK.

414 Loke MH (2000) Electrical Imaging Survey for Environmental and Engineering Studies: A 415 practical guide to 2D and 3D surveys. https://pdf4pro.com/amp/view/electrical-imaging-surveys416 for-environmental-and-39b461.html. Accessed on 12 May 2020.

418 Loke MH (2004) Tutorial: 2-D and 3-D electrical imaging surveys. 419 https://sites.ualberta.ca/ unsworth/UA-classes/223/loke_course_notes.pdf . Accessed on 13 May $420 \quad 2020$.

422 Loke MH, Barker RD (1996) Rapid least squares inversion of apparent resistivity pseudo-section 423 by a quasi-Newton method. Geophysical prospecting. 44(1): 131-152. 
425 Margarita M, Stephen K, Derek R, Philip C, Pantelis S, Filippos V (2010) Geological and 426 Electrical Resistivity Tomography surveys applied to model the tectonic environment of the 427 Kastelli-Kissamou basin, northwestern Crete, Greece. In: Schmitter E, Mastorakis N (eds) (WHH 428 '10): Water \& Geoscience. $5^{\text {th }}$ IASME/WSEAS international on Water Hydraulics and Hydrology, 429 UK, February 2010, WSEAS Press, 184-189.

Nguyen TF, Garambois DS, Jongmans EP, Loke MH (2005) Image processing of 2D resistivity data for imaging faults. Journal of Applied Geophysics 57(1): 260-277.

Nwajide CS (1990) Cretaceous Sedimentation and Palaeogeography of the Central Benue Trough: The Benue Trough Structure and Evolution, Friedr. Vieweg and Sohn, Braunchweig/Wiesbaden.

Nwajide CS (2013) Geology of Nigeria’s Sedimentary Basin. CSS Bookshop Limited, Lagos.

Obi GC, Okogbue CO (2004) Sedimentary response to tectonism in the Campanian-Maastrichtian succession Anambra Basin, Southeastern Nigeria. Journal of African Earth Sciences 38(1):99440108.

442 Osinowo OO, Falufosi MO (2018) 3D Electrical Resistivity Imaging (ERI) for subsurface 443 evaluation in pre-engineering construction site investigation. NRIAG Journal of Astronomy and 444 Geophysics 7:309-317.

445 Oyedele KF, Olorode DO (2010) Site Investigations of Subsurface Conditions Using Electrical 446 Resistivity Method and Cone Penetration Test at Medina Estate, Gbagada, Lagos, Nigeria. World 447 Applied Sciences Journal 11(9): 1097-1104.

448 Oyeyemi KD, Olofinnade OM (2016) Geoelectrical-Geotechnical Studies for Near Surface 449 Characterization, Case History: Lagos, SW Nigeria. EJGE 16 (10): 3735-3750.

451 Reijers TJA (1996) Selected Chapters on Geology: Sedimentary Geology and Sequence 452 Stratigraphy in Nigeria \& Three Case Studies and a Field Guide. Shell Petroleum Development 453 Company of Nigeria. 
454 Reynolds JM (2011) An introduction to applied and environmental geophysics. John Wiley \& 455 Sons Ltd, UK.

457 Reyment RA (1965) Aspects of the Geology of Nigeria: The Stratigraphy of the Cretaceous and 458 Cenozoic Deposits. Ibadan University Press, Ibadan.

459 Roy S, Bhalla SK (2017) Role of Geotechnical Properties of Soil on Civil Engineering 460 Structures. Resources and Environment 7(4):103-109.

461 Samouelian A, Cousin I, Tabbagh A, Bruand A, Richard G (2005) Electrical Resistivity Survey in 462 Soil Science: A Review. Soil \& Tillage Research 83(1):173-193.

463 Schmutz M, Ghorbani A, Vaudelet P, Revil A (2011) Spectral Induced Polarization Detects Cracks 464 and Distinguishes between Open- and Clay-filled Fractures. Journal of Environmental and 465 Engineering Geophysics 16(2):85-91.

466 Shorts KC, Stauble AJ (1967) Outline of Geology of Niger. The American Association of 467 Petroleum Geologist Bulletin 51(5):761-779.

469 Sitharam TG (2013) Shallow Foundations: Advanced Foundation Engineering. Indian Institute of 470 Science, Bangalore.

472 Soupios PM, Georgakopoulos P, Papadopoulos N, Saltas V, Andreadakis A, Vallianatos F, Sarris 473 A, Makris JP (2007) Use of Engineering Geophysics to Investigate a Site for Building Foundation. 474 Journal of Geophysics and Engineering 4(1):94-103.

475 Ugwu GZ, Ezema PO (2013) 2D Electrical Resistivity Imaging for the Investigation of the 476 Subsurface Structures at the Proposed Site for Kauridan Estate at Ibagwa - Nike, Southeastern 477 Nigeria. International Journal of Scientific Research in Knowledge 1(12):528-535.

478 Vogelsang D (1995) Environmental Geophysics - A Practical Guide. Springer, Verlag. 479

480 Telford WM, Geldart LP, Sheriff RE (1990) Applied Geophysics. Cambridge University Press, 481 Cambridge. 
483 Terzaghi K, Peck RB, Mesri G (1996) Soil Mechanics in Engineering Practice. John Wiley Sons 484 Inc, New York.

Figure captions

487 Figure 1. Location and Geology of the study area

488 Figure 2. Two forms of measurement of overvoltage $\left(\mathrm{V}_{\mathrm{p}}\right)$ at (a) discrete time interval and (b) by 489 the area below the overvoltage curve, A.

490 Figure 3. Design of Geophysical Survey Lines

491 Figure 4. Tomography Result for Profile line One. (a) Profile Line One Electrical Resistivity 492 Tomography $\left(\mathrm{ERT}_{1}\right)$, (b) Profile Line One Induced Polarization Tomography (IPT 1 )

493 Figure 5. Tomography Result for Profile Line Two. (a) Profile Line Two Electrical Resistivity 494 Tomography (ERT2), (b) Profile line Two Induced Polarization Tomography (IPT 2$)$

495 Figure 6. Tomography Result for Profile Line Three. (a) Profile Line Three Electrical Resistivity 496 Tomography $\left(\mathrm{ERT}_{3}\right)$, (b) Profile line Three Induced Polarization Tomography (IPT $)_{3}$

497 Figure 7. Tomography Result for Profile Line Four. (a) Profile Line Four Electrical Resistivity 498 Tomography $\left(\mathrm{ERT}_{4}\right)$, (b) Profile line Four Induced Polarization Tomography (IPT4)

499 Figure 8. Fracture Zone A delineation. (a) 3D plot of measured apparent resistivity for profile line 500 Three and Profile line one revealing fracture zone. (b) $2.5 \mathrm{D}$ view of $\mathrm{ERT}_{1}-\mathrm{ERT}_{3}$ revealing 501 fracture zone (c) 2.5D view of $\mathrm{IPT}_{1}-\mathrm{IPT}_{3}$ revealing fracture zone, (d) Google earth image showing 502 profile lines I and 3.

503 Figure 9. Fracture Zone B delineation. (a) 2.5D view of $\mathrm{ERT}_{2}-\mathrm{ERT}_{4}$ revealing fracture zone (b) $5042.5 \mathrm{D}$ view of $\mathrm{IPT}_{2}-\mathrm{IPT}_{4}$ revealing fracture zone. 
505 Figure 10. Field photographs validating the presence of fracture.

506 Figure 11. Delineated facture zones on Google Map view.

508 Declarations

\section{- Availability of data and materials}

The datasets used and/or analysed during the current study are available from the corresponding author on reasonable request.

\section{- Competing Interests}

The authors declare that they have no competing interests.

\section{- Funding}

\section{- Authors' Contribution}

Okechukwu Nnebedum coordinated the data acquisition, analyses, and interpretation. He also compiled the manuscript. Ogbonnaya Igwe designed and supervised the work. He also attracted the funds. Stanley I. Ifediegwu was instrumental in data collection and analyses as well as map production. All authors read and approved the final manuscript.

\section{- Acknowledgements}




\section{2}

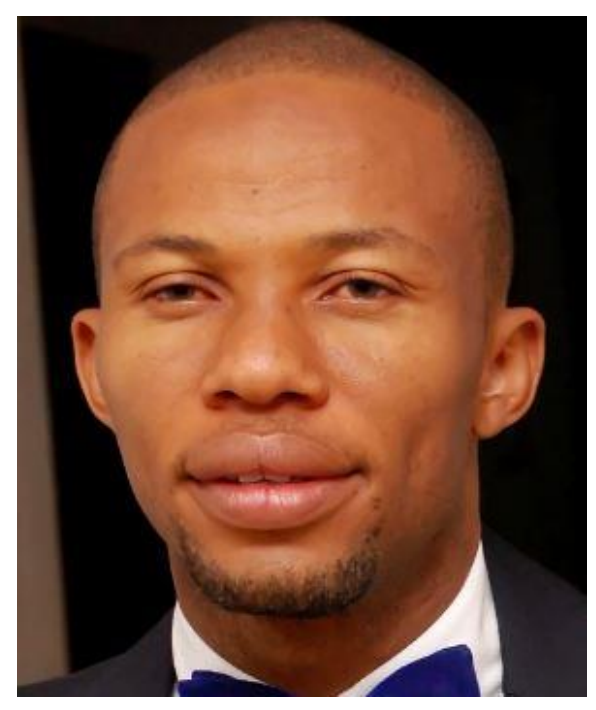

533 Donald Okechukwu Nnebedum (PhD) graduated from the University of Nigeria Nsukka in 2021.

534 His research interest is in geophysical data acquisition, processing, and interpretation. Email:

535 okechukwu.nnebedum@unn.edu.ng

536

537 